\title{
My Vision for Family Medicine
}

Yeri Park, MD

(Fam Med. 2021;53(7):638-9.)

doi: 10.22454/FamMed.2021.346991

Published Online First June 21, 2021

I

$t$ is a busy evening in the emergency room. I walk through the eerie corridor with the loud beeps of the IV machines ringing in my ears; I arrive in the room of my next patient being admitted. I introduce myself with the same sentence, "Hello, I'm Dr Park. I am a resident who will take care of you tonight. I work with your family doctor." With that sentence, my patient's eyes brighten. Eyes that were once filled with uncertainty and fear of being admitted to the hospital, immediately change to relief knowing that I was someone who worked with their doctor. This type of encounter is common in our training. Many patients tell me that they have known their primary care physician for numerous yearstheir family doctors knew everything about their health, took care of their children, cousins, parents, and next-door neighbors. These patients trust their primary care doctors (most of whom are my faculty members) and in turn also trust me to take care of them. Through long, caring relationships, family physicians provide a sense of comfort, trust, and reassurance, which I find to be rewarding and attractive aspects of our field.

As I complete my final months in residency, I am excited to envision my career as I reflect on my own training. Did I create that trust in my patients? What continues to inspire me for my future practice and the future of our field? When I applied to residency, my goal was simple: become a family physician who would provide excellent care and advocate for my patients. Learning patient care came with time, however it was the following three aspects that I learned from my faculty that continues to bring me joy in our field similar to the day I applied to the Match.

\section{Full Scope}

As a resident, I am inspired by faculty members who practice full-scope family medicine. Our family medicine training should continue to encourage exposure to a variety of experiences including pediatrics, maternity care, and procedures, with the goal of achieving competency in these areas, allowing incorporation of this knowledge into future careers. There are fewer family physicians providing pediatric and maternity care despite a need in rural and underserved areas. ${ }^{1,2}$ Procedures performed by primary care physicians also continue to decrease. These trends will lead to a decline in exposure to clinicians who practice with breadth of skills, leading to a cycle in which trainees cannot imagine themselves in full-spectrum practice. While factors such as lifestyle choices and area of practice will ultimately play a role in a trainee's decision to provide comprehensive care, continued exposure to physicians with these skills throughout residency training will allow residents to build confidence as well as competence when considering incorporating these aspects of practice into their future careers. Importantly, recruiting faculty members who practice full-scope family medicine and model the range of possibilities within family medicine practice will allow residents to see themselves in such roles.

\section{Adaptability}

I am inspired by how faculty members understand and can change health systems. Society's need for physicians will continue to change, and in order to meet these needs,

From the Lawrence Family Medicine Residency, Lawrence, MA. 
understanding health systems should be emphasized. With the opioid epidemic, physicians learned and began to provide medications for opioid use disorders. The COVID-19 pandemic entirely changed our norm of how we practice medicine to include modalities such as telehealth. These two examples were made possible because residents and faculty developed innovative ideas together to meet the needs of our patients, utilizing knowledge of health systems to implement change. Ideas remain simply ideas if they cannot be put into action. Innovative ideas should be supported, and the development of skills to incorporate these ideas into our current systems will allow family physicians to be at the frontline of medicine.

\section{Community Involvement}

Finally, I am inspired by faculty who actively engage with our community, not only in hospitals or clinics, but in homes, long-term facilities, shelters, streets and local organizations. Our patients' zip codes determine the outcome of their health to a greater extent than genetics or biology; disparities in health care exist with worse health outcomes, especially in people of color and low socioeconomic status. Learning about social determinants of health is not enough. Family physicians are not only physicians for individuals but we are physicians for our communities. Community engagement and participation should be considered an essential part of our training to become true advocates for the population that we serve, and we should assist in implementing upstream ideas together with our community members to improve their health.

\section{The Future}

The new Accreditation Council for Graduate Medical Education (ACGME) guidelines will ask many questions about what and how to teach future family physicians. Breadth of care and training to competency, understanding of health systems and community engagement are aspects of family medicine training that should be considered essential components in the training. In order to do so, we need faculty members with a wide variety of skills and areas of expertise, such as those who are experts at viral hepatitis and round on inpatient medicine, those who transform prenatal care to a COVID-appropriate telehealth model, to those who teach ultrasound and deliver babies. They will serve as role models of the possibility of providing full-spectrum care, share innovative ideas, and understand health care systems to implement changes based on what the population needs. These role models serve as guides for residents at work, and importantly, toward the first chapters in our lifelong careers. I hope that the ACGME revisions will provide guidelines that will train the next set of physicians broadly enough to continue to brighten patients' eyes in times of uncertainty.

PRESENTATIONS: An initial draft of this commentary was submitted for review during the Starfield Summit "Reenvisioning Family Medicine,” December 6-7, 2020.

ACKNOWLEDGMENT: The author acknowledges Drs Timothy Graham and Anthony Valdini for their guidance and review of this commentary.

CORRESPONDENCE: Address correspondence to Dr Yeri Park, Lawrence Family Medicine Residency, 34 Haverhill St, Lawrence, MA 01841. 978-686-0090. yeri.park@glfhc.org.

\section{References}

1. Bazemore AW, Makaroff LA, Puffer JC, et al. Declining numbers of family physicians are caring for children. $J$ Am Board Fam Med. 2012;25(2):139-140. doi:10.3122/jabfm.2012.02.110203

2. Tong ST, Makaroff LA, Xierali IM, et al. Proportion of family physicians providing maternity care continues to decline. J Am Board Fam Med. 2012;25(3):270-271. doi:10.3122/ jabfm.2012.03.110256

3. Peckham C. Medscape physician lifestyle report 2016: bias and burnout. Medscape. https://www.medscape.com/slideshow/lifestyle-2016-overview-6007335. Published January 13, 2016. Accessed March 24, 2021. 